\title{
COVID-19 and its relation to pregnancy and neonates: a systematic review
}

Gerson Aparecido Foratori-Junior 1

(iD) https://orcid.org/0000-0003-4760-8948

Victor Mosquim 2

(iD https://orcid.org/0000-0003-0442-5690

Thais Marchini de Oliveira Valarelli 3

(iD) https://orcid.org/0000-0003-3460-3144
Maria Aparecida de Andrade Moreira Machado 4

(iD) https://orcid.org/0000-0003-3778-7444

Silvia Helena de Carvalho Sales-Peres 5

(iD) https://orcid.org/0000-0003-3811-7899

1,3,4,5 Departamento de Odontopediatria, Ortodontia e Saúde Coletiva. Faculdade de Odontologia de Bauru. Universidade de São Paulo. Alameda Dr. Octávio Pinheiro Brisolla, 9-75. Vila Universitária. Bauru, SP, Brasil. CEP: 17.012-901. E-mail: shcperes@usp.br

2 Departamento de Dentística, Endodontia e Materiais Odontológicos. Faculdade de Odontologia de Bauru. Universidade de São Paulo. Bauru, SP, Brasil.

\begin{abstract}
Objectives: this study systematically reviewed the literature in order to better understand the association among COVID-19, pregnancy and neonates.

Methods: MEDLINE, EMBASE, Web of Science, BVS and SCOPUS were assessed, considering the terms: (covid 19 OR covid-19 OR novel coronavirus OR 2019 novel coronavirus OR 2019-nCoV OR sarscov 2 OR sars-cov-2 OR sarscov2 OR sars cov-2) AND (pregnancy OR pregnant OR pregnant women OR gestation OR gestational) AND (infant OR fetal OR neonatal). Thirty full-text were included (408 pregnant women, 11 non-pregnant women and 279 neonates).

Results: fever (45.83\%) and cough (31.61\%) were the main symptoms of COVID-19 during the pregnancy. Low levels of lymphocytes (32.10\%), elevated levels of C-reactive protein (32.35\%); leukocytosis (29.41\%); neutrophil (5.88\%); and radiographic alterations on chest CT, $x$-ray or ultrasound (45.84\%) were the main laboratorial findings. Cesarean delivery and preterm were registered in 239 and 49 cases, respectively. Ten neonates tested positive for SARS-CoV-2.

Conclusion: when COVID-19 pneumonia affects women during pregnancy, the symptoms are similar to those experienced by non-pregnant women. In addition, there is still no plausible evidence suggesting vertical transmission of SARS-CoV-2 virus from mother to child. Key words COVID-19, SARS-CoV-2, Pregnancy, Childbirth, Newborn
\end{abstract}

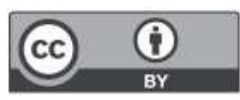




\section{Introduction}

Currently known as COVID-19, SARS-CoV-2 virus (Severe Acute Respiratory Syndrome-related coronavirus 2) is a public health emergency of international concern. It has been suggested that previous complications may be risk factors for adverse outcomes related to COVID-19 such as cardiovascular disease, diabetes, hypertension, and chronic obstructive pulmonary disease. ${ }^{1-3}$

Regarding symptomatology, similarities of clinical features between 2019-nCoV and previous beta coronavirus infections has been found. Most patients present fever, dry cough, dyspnea, and bilateral patchy pattern and/or ground-glass opacities on chest computerized tomography (CT) scans. ${ }^{1}$ Nonetheless, the report from Huang et al. 1 mainly focused on nonpregnant women. Contrasting data are found on maternal and neonatal outcomes of pregnant women with COVID-19 pneumonia.

Prior December 2019, others six coronaviruses were known to infect people: 229E, OC43, NL63, HKU1, SARS-CoV, and MERS-CoV (Middle East Respiratory Syndrome coronavirus). Among these, 229E, OC43, NL63, and HKU1 can be vertically transmitted from mothers to neonates through the placenta, 4,5 whilst there is no evidence of vertical transmission of SARS-CoV and MERS-CoV.5,6 Nevertheless, an epidemiological research presented that 2019-nCoV was more contagious than SARS$\mathrm{CoV}$, although, its nucleotide sequences were very similar ( $82 \%$ homologous with SARS-CoV). ${ }^{7}$

Moreover, it has been stated that COVID-19 infections in pregnant women generally result in mild or moderate symptoms, and many infected pregnant women do not present any symptoms, 8,9 which may also lead to a high risk of neonatal infection during labor. However, the clinical characteristics and potential vertical transmission of COVID19 pneumonia in pregnant women is still new and has not been entirely clarified. 8,10 Therefore, it is important to report the most frequent symptoms of this disease in pregnant women and neonates, as well as to understand the risk of infection that labor imposes to the neonates' health. Based on this rationale, this study aimed to systematically review the available literature in order to better understand the association among COVID-19, pregnancy and neonates.

\section{Methods}

This systematic review was conducted without patient involvement. Patients were not involved in any way during the review of the available literature, nor during the writing or editing of this document for readability or accuracy.

The search strategy followed the indications of the National Health Service Center for Reviews and Dissemination and Preferred Reporting Items for Systematic Reviews and Meta-Analyses (PRISMA) guidelines. Also, this systematic review was registered in International Prospective Register of Systematic Reviews (PROSPERO) with protocol CRD42020177354 (https://www.crd.york.ac.uk/ prospero).

A systematic revision of relevant studies published in the literature was conducted on May 22nd, 2020, considering the period between December 1st, 2019 to May 22nd, 2020. The following database were explored: MEDLINE database (Entrez PubMed, www.ncbi.nim.nih.gov), EMBASE, Web of Science, BVS/LILACS and SCOPUS, considering the main MeSH (Medical Subject Headings) terms: (covid 19 OR covid-19 OR novel coronavirus OR 2019 novel coronavirus OR 2019-nCoV OR sarscov 2 OR sars-cov-2 OR sarscov2 OR sars cov-2) AND (pregnancy OR pregnant OR pregnant women OR gestation OR gestational) AND (infant OR fetal OR neonatal). To identify relevant article, titles and abstracts of retrieved papers were exported to Endnote Web where duplicates were identified and removed by two reviewers (GAFJ and VM). It is important to highlight that, in order to identify missing studies, we also hand searched the reference lists of the studies included.

As eligibility criteria, we considered case reports, case series and clinical researches in English, Portuguese and Spanish published in peerreviewed journals, that have addressed epidemiological, clinical features of COVID-19 and its association with pregnancy and neonates. Duplicate publications and articles that did not correspond to the objectives of this review were excluded. Similarly, publications without a research or case report, such as: review articles; descriptive studies; opinion article; correspondence; editorials; letters; and with only children's cases were also excluded. Figure 1 shows the steps of the literature search.

Two highly experienced researchers (GAFJ and $\mathrm{VM}$ ) were previously trained regarding to criteria that were defined in this study and after they were responsible for searching the literature, applying inclusion and exclusion criteria, selecting the studies and independently extracting the data. There was a good concordance coefficient between reviewers (Kappa index=0.91). Discordances between the authors were discussed and agreed upon with a third 


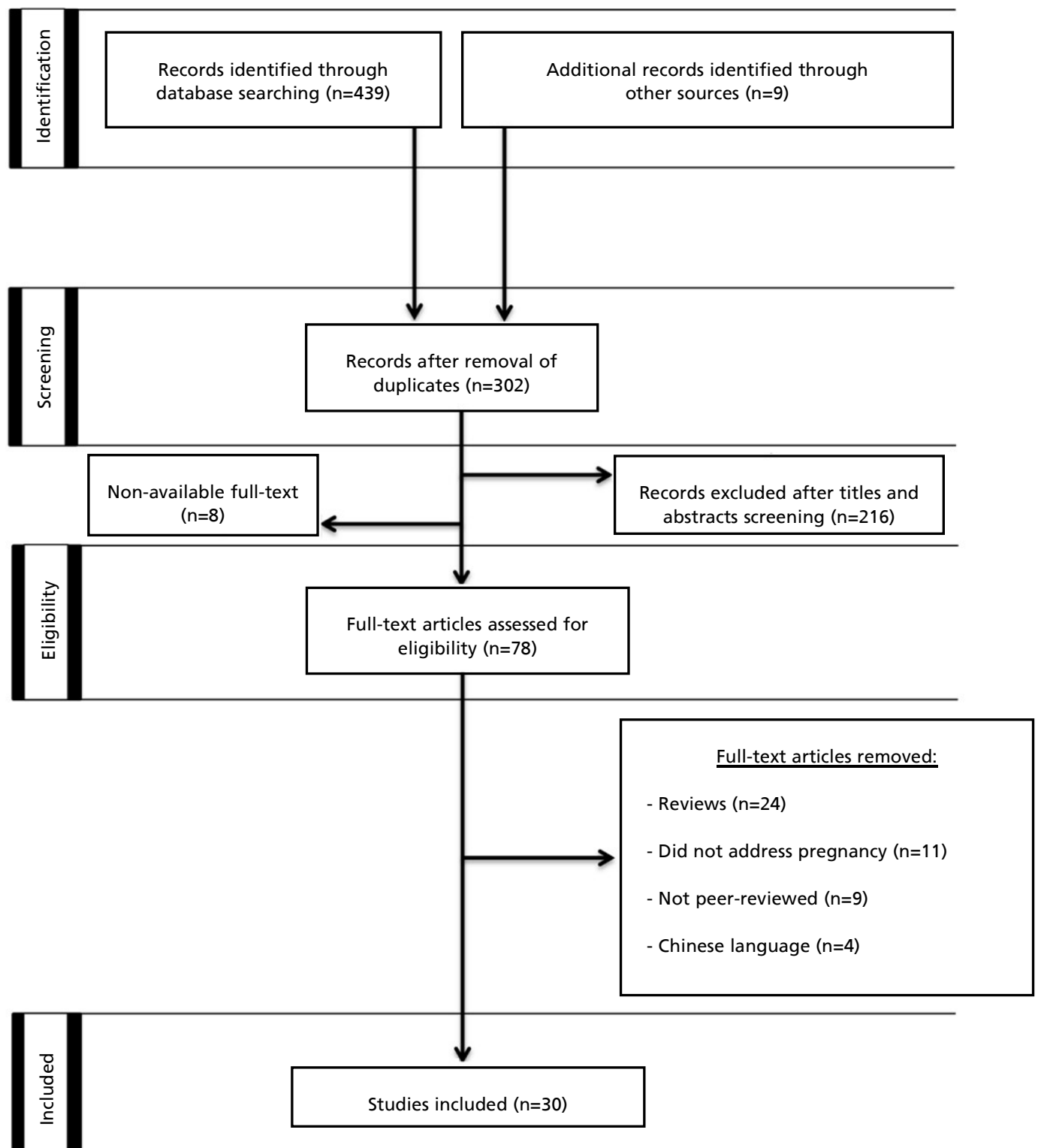


author (SHCSP).

Studies assessed in this review were classified and stored by: main author, publication year, study design, sample/participants, maternal age, consequences for pregnant women, consequences for neonates, absence/presence of vertical transmission.

The initial search identified 439 studies (181 from PubMed, 135 from EMBASE, 71 from BVS, 33 from Web of Science and 19 from SCOPUS). After, nine sources were manually inserted by analyzing the references list of previous studies. Fifty-five sources remained on screening step after duplicates exclusion.

Following screening of titles and abstracts, 216 sources were excluded due to the following reasons: reviews; author reply/ comment/ correspondence/ expert comment/ guideline/ letter to editor/ in websites; not correspond to the objectives of this review; not peer-reviewed; language. Besides that, one full-text study was not found.

Seventy-eight articles in full text were assessed. Thirty were considered with good relevance, among them: clinical research $(\mathrm{n}=1)$; case-control $(\mathrm{n}=1)$; retrospective review of cases $(\mathrm{n}=10)$; case series $(n=4)$; case reports $(n=14)$. Forty-eight were removed due to the following reasons: reviews $(n=24)$; did not address pregnancy $(n=11)$; not peerreviewed $(n=9)$; Chinese language $(n=4)$.

\section{Results}

A total of 408 pregnant women was considered. The mean age of all pregnant women in the 30 studies included in this review was 32.46 years old. Also, among the studies included in this review, 11 nonpregnant women and 279 neonates were considered.

The main symptoms of this disease in pregnant women were fever $(45.83 \%)$ accompanied or not by fatigue, cough (31.61\%), myalgia (15.19\%), dyspnea $(11.76 \%)$, sore throat $(3.92 \%)$ and diarrhea $(1.96 \%)$. Other less frequent symptoms, such as shortness of breath, headache and anemia were reported (Table 1).

The most frequent laboratorial features were elevated levels of C-reactive protein $(32.35 \%)$; low levels of lymphocytes (32.10\%); leukocytosis (29.41\%); neutrophil levels above the normal range (5.88\%); radiographic alterations on chest $\mathrm{CT}$ or $\mathrm{x}$ ray $(45.34 \%)$, because of viral pneumonia that is characterized by decreased diffuse and unilateral or bilateral ground-glass opacities, patchy lung consolidation and blurred borders (Table 2).

The main findings of this study point out that, of the 279 neonates, only ten tested positive for SARS-
$\mathrm{CoV}-2$, indicating a low risk of vertical transmission of the disease (Table 3). Delivery outcomes, characteristics of infants at birth and evidence of vertical transmission are also displayed in Table 3.

\section{Discussion}

Due to their immunosuppressed state and physiological and adaptive changes, pregnant women are more susceptible to pneumonia and other respiratory pathogens. Nonetheless, our results highlighted that fever and cough were the main clinical features of COVID-19 during pregnancy, but asymptomatic cases are common. Several studies reported false negative diagnosis by RT-PCR, whilst chest CT and $\mathrm{X}$-rays analyses seem to be a fast and highly reliable diagnostic method. Also, vertical transmission from mother to neonates seems unlikely, yet, the available data addressing this topic is still scarce. Overall, data are limited in relation to the association of the outcomes, since population-based clinical studies are still scarce and most studies have low strength of scientific evidence.

Chen et al. 10 reported that the main symptoms of SARS-CoV-2 infection in pregnant women are fever and cough, with lower frequency for myalgia, malaise, sore throat, shortness of breath and diarrhea. Laboratorial findings also report that lymphopenia and increased ALT and AST levels are frequent. These findings are in accordance with the findings of this systematic review, where fever $(45.83 \%)$ and cough $(31.61 \%)$ were the most frequent symptoms among the 408 pregnant women analyzed in this review, followed by myalgia $(15.19 \%)$, dyspnea $(11.76 \%)$, sore throat $(3.92 \%)$ and diarrhea (1.96\%). ${ }^{5,8-36}$ Laboratorial tests reported decreased levels of lymphocytes $(32.10 \%)$ and increased levels of C-reactive protein $(32.35 \%)$ as frequent conditions, followed by leukocytosis (29.41\%) and increased neutrophil ratio (5.88\%).

Medonza et al. 37 reported that preeclampsia-like syndrome is one symptom of COVID-19, but its cause is different from obstetric preeclampsia and therefore not connected with placental failure. In addition, preeclampsia-like syndrome can resolve spontaneously following recovery from severe pneumonia and may not be an obstetric indication for delivery.

Other main findings seen in the reviewed studies was alterations on chest CT.5,9,12,13,15,20,21,2325,30,31,33-35 More than $45 \%$ of patients included in this review presented alterations upon chest $\mathrm{CT}$, $\mathrm{x}$ ray or ultrasound. These findings, along with the study of Liu et al. 27 suggest than CT images seem to 
Table 1

Description of pregnant women's clinical characteristics in the selected studies.

\begin{tabular}{lllcl}
\hline Author (year) & Study design & \multicolumn{1}{c}{ Participants } & Location & Clinic \\
\hline Alonso Diaz et al.,11 (2020) & Case report & $\begin{array}{l}1 \text { pregnant woman; } \\
1 \text { neonate }\end{array}$ & Spain & - Fever; \\
& & & - Cough; \\
& & & - Dyspnea \\
Alzamora et al.,12 (2020) & Case report & 1 pregnant woman; & & - Fever; \\
& & 1 neonate & Peru & - Fatigue; \\
& & & - Dyspnea; \\
& & & - Indisposição
\end{tabular}

Breslin et al.,13 (2020)

Case series

29 pregnant women with

USA

- Febre $(n=14)$;

symptomatic admitted

Cough $(n=19)$;

- Myalgia or fatigue $(n=11)$;

14 pregnant women

asymptomatic admitted

- Dyspnea $(n=7)_{i}$

- Chest pain $(n=5)$;

- Headache $(n=8)$

Breslin et al.,14 (2020)

Case series

7 pregnant women

USA

- Fever $(n=2)$;

- Cough ( $n=3)$;

- Myalgias ( $n=3)$;

- Chest pain $(n=2)$;

- Headache $(n=2)$

Buonsenso et al.,15 (2020)

Case series

4 pregnant women;

Italy

Fever $(n=3)$;

2 neonates

- Cough $(n=4)$;

- Dyspnea $(n=1)$;

- Ageusia/anosmia ( $n=1)$ 
Description of pregnant women's clinical characteristics in the selected studies.

\begin{tabular}{|c|c|c|c|c|}
\hline Author (year) & Study design & Participants & Location & Clinical features of pregnant women \\
\hline Chen et al.,10 (2020) & $\begin{array}{c}\text { Retrospective case } \\
\text { review }\end{array}$ & $\begin{array}{l}9 \text { pregnant women; } \\
9 \text { neonates }\end{array}$ & China & $\begin{array}{l}\text { - Fever }(n=7) ; \\
\text { - Postpartum fever }(n=6) \text {; } \\
\text { - Myalgia }(n=3) ; \\
\text { - Malaise }(n=2) ; \\
\text { - Cough }(n=4) ; \\
\text { - Dyspnea }(n=1) ; \\
\text { - Sore throat }(n=2) ; \\
\text { - Diarrhea }(n=1) ; \\
\text { - Influenza }(n=1)\end{array}$ \\
\hline Chen et al.,16 (2020) & Case series & $\begin{array}{l}17 \text { parturients; } \\
17 \text { neonates }\end{array}$ & China & $\begin{array}{l}\text { - Anemia }(n=5) \text {; } \\
\text { - Gestational hypertension }(n=1) \text {; } \\
\text { - Gestational diabetes }(n=2) ; \\
\text { - Mild fever without chills }(n=4) \text {; } \\
\text { - Cough }(n=4) ; \\
\text { - Fatigue }(n=1) \\
\text { - Chest distress }(n=2) \\
\text { - Dyspnea }(n=1) \text {; } \\
\text { - Diarrhea }(n=1)\end{array}$ \\
\hline Chen et al.,17 (2020) & Case series & $\begin{array}{l}4 \text { pregnant women } \\
4 \text { neonates }\end{array}$ & China & $\begin{array}{l}\text { - Fever }(n=3) \\
\text { - Cough }(n=2) ; \\
\text { - Myalgia or fatigue }(n=2) ; \\
\text { - Headache }(n=2) ; \\
\text { - Reduced fetal movement }(n=1) ; \\
\text { - Dyspnea }(n=1) ; \\
\text { - Severe dyspnea after delivery }(n=1)\end{array}$ \\
\hline
\end{tabular}


Description of pregnant women's clinical characteristics in the selected studies.

\begin{tabular}{|c|c|c|c|c|}
\hline Author (year) & Study design & Participants & Location & Clinical features of pregnant women \\
\hline Fan et al., ${ }^{18}(2020)$ & Case series & $\begin{array}{l}2 \text { pregnant physicians; } \\
2 \text { neonates }\end{array}$ & China & $\begin{array}{l}\text { - Mild fever }(n=2) ; \\
\text { - Rash }(n=1) ; \\
\text { - Nasal congestion }(n=2) ; \\
\text { - Sore throat }(n=1)\end{array}$ \\
\hline Ferrazzi et al..,8 (2020) & $\begin{array}{l}\text { Retrospective case } \\
\text { review }\end{array}$ & $\begin{array}{l}42 \text { pregnant women; } \\
42 \text { neonates }\end{array}$ & Italy & $\begin{array}{l}\text { - Fever }(n=20) \\
\text { - Cough }(n=18) \\
\text { - Dyspnea }(n=8) \\
\text { - Myalgia }(n=7) \\
\text { - Diarrhea }(n=2)\end{array}$ \\
\hline Gidlöf et al..,19 (2020) & Case report & $\begin{array}{l}1 \text { pregnant woman; } \\
2 \text { neonates }\end{array}$ & Sweden & $\begin{array}{l}\text { - Pregnant women with high BMI; preeclampsia and gestational } \\
\text { diabetes mellitus - (clinical features complicated by COVID-19); } \\
\text { - Headache; } \\
\text { - Sore throat; } \\
\text { - Malaise; } \\
\text { - Hypertension }\end{array}$ \\
\hline $\begin{array}{l}\text { Gonzáles Romero et al.,20 } \\
(2020)\end{array}$ & Case report & $\begin{array}{l}1 \text { pregnant woman; } \\
1 \text { neonate }\end{array}$ & Spain & $\begin{array}{l}\text { - Fever; } \\
\text { - Cough; } \\
\text { - Sore throat }\end{array}$ \\
\hline $\begin{array}{l}\text { Hantoushzadeh et al.,21 } \\
\text { (2020) }\end{array}$ & $\begin{array}{l}\text { Retrospective case } \\
\text { review }\end{array}$ & $\begin{array}{l}9 \text { pregnant women; } \\
7 \text { neonates }\end{array}$ & Iran & $\begin{array}{l}\text { - Fever }(n=9) ; \\
\text { - Cough }(n=9) ; \\
\text { - Dyspnea }(n=6) ; \\
\text { - Sore throat }(n=1) ; \\
\text { - Deaths }(n=7)\end{array}$ \\
\hline
\end{tabular}


Description of pregnant women's clinical characteristics in the selected studies.

\begin{tabular}{|c|c|c|c|c|}
\hline Author (year) & Study design & Participants & Location & Clinical features of pregnant women \\
\hline lqbal et al.,22 (2020) & Case report & $\begin{array}{l}1 \text { pregnant woman; } \\
1 \text { neonate }\end{array}$ & USA & $\begin{array}{l}\text { - Fever; } \\
\text { - Chills; } \\
\text { - Dry cough; } \\
\text { - Myalgia }\end{array}$ \\
\hline Kalafat et al.,23 (2020) & Case report & $\begin{array}{l}1 \text { pregnant woman; } \\
1 \text { neonate }\end{array}$ & Turkey & $\begin{array}{l}\text { - Cough; } \\
\text { - Dyspnea; } \\
\text { - Swollen left leg }\end{array}$ \\
\hline Li et al..,24 (2020) & Case-control & $\begin{array}{l}\text { Case groups: } \\
\text { - Confirmed cases who were tested } \\
\text { positive for SARS-CoV-2 }(n=16) ; \\
\text { - Suspected cases with typical chest CT } \\
\text { imaging but negative in RT-PCR tests } \\
\text { ( } n=18) ; \\
\text { Control groups: } \\
\text { - Women admitted during January } 24 \text { - } \\
\text { February 29, } 2020(n=120) ; \\
\text { - Women admitted during January } 24 \text { - } \\
\text { February 11, } 2019(n=121) ; \\
\text { Neonates: } \\
\text { - Confirmed case group }(n=17) ; \\
\text { - Suspected case group }(n=19) ; \\
\text { - Control } 2020(n=121) ; \\
\text { - Control } 2019(n=121)\end{array}$ & China & $\begin{array}{l}\text { Fever on admission: } \\
\text { - Confirmed case group }(n=4) \text {; } \\
\text { - Suspected case group }(n=1) ; \\
\text { Cough: } \\
\text { - Confirmed case group }(n=0) ; \\
\text { - Suspected case group }(n=1) ; \\
\text { Sore throat: } \\
\text { - Confirmed case group }(n=0) ; \\
\text { - Suspected case group }(n=1) ; \\
\text { Dyspnea: } \\
\text { - Confirmed case group }(n=0) ; \\
\text { - Suspected case group }(n=1)\end{array}$ \\
\hline
\end{tabular}


Description of pregnant women's clinical characteristics in the selected studies.

\begin{tabular}{|c|c|c|c|c|}
\hline Author (year) & Study design & Participants & Location & Clinical features of pregnant women \\
\hline Li et al.,25 (2020) & Case report & $\begin{array}{l}1 \text { pregnant woman; } \\
1 \text { neonate }\end{array}$ & China & $\begin{array}{l}\text { - Dry cough and fever }\left(37.2^{\circ} \mathrm{C}\right) \\
\text { - Chest auscultation slightly thicker in the right lung }\end{array}$ \\
\hline Liu et al., 26 (2020) & $\begin{array}{l}\text { Retrospective case } \\
\text { review }\end{array}$ & $\begin{array}{l}15 \text { pregnant women; } \\
11 \text { neonates }\end{array}$ & China & $\begin{array}{l}\text { - Fever }(n=13) \\
\text { - Cough }(n=9) \\
\text { - Fatigue }(n=4) \\
\text { - Muscle pain }(n=3) \\
\text { - Dyspnea }(n=1) \\
\text { - Sore throat }(n=1) \\
\text { - Diarrhea }(n=1) \\
\text { - Postpartum fever }(n=1)\end{array}$ \\
\hline Liu et al.,27 (2020) & Clinical research & $\begin{array}{l}41 \text { pregnant women*; } \\
11 \text { non-pregnant adults } \\
\text { * } 16 \text { pregnant women were SARS-CoV-2 } \\
\text { positive; } \\
17 \text { laboratorial-negative but with typical }\end{array}$ & China & $\begin{array}{l}\text { - Initial onset of fever in either laboratorial-confirmed }(n=7 / 16) \text { or } \\
\text { clinically-diagnosed }(n=9 / 25) \text { pregnant women; } \\
\text { - Cough }(n=6 / 16 \text { and } 9 / 25) \text {; } \\
\text { - Shortness of breath }(n=2 / 16 \text { and } 3 / 25) \text {; } \\
\text { - Fatigue }(n=3 / 16 \text { and } 2 / 25) \text {; } \\
\text { - Loss of appetite }(n=2 / 16 \text { and } 1 / 25) \text {; } \\
\text { - Postpartum fever }(n=5 / 16 \text { and } 9 / 25)\end{array}$ \\
\hline
\end{tabular}

CT features of COVID-19 pneumonia;

and the other 8 did not undergo SARS

CoV-2 test

Retrospective case 13 pregnant women

review

13 neonates
China
- Fever, range $37.3-39.0^{\circ} \mathrm{C}$, mostly accompanied with fatigue $(\mathrm{n}=10)$;

- Dyspnea $(n=3)$;

ICU admitted with MODS including ARDS, requiring intubation and mechanical ventilation, acute hepatic failure, acute renal failure and septic shock $(n=1)$ 
Description of pregnant women's clinical characteristics in the selected studies.

\begin{tabular}{|c|c|c|c|c|}
\hline Author (year) & Study design & Participants & Location & Clinical features of pregnant women \\
\hline Song et al.,29 (2020) & Case report & $\begin{array}{l}1 \text { pregnant woman; } \\
1 \text { neonate }\end{array}$ & China & $\begin{array}{l}\text { - Fever; } \\
\text { - Cough; } \\
\text { - Generalized myalgia; } \\
\text { - Decreased breath sounds; } \\
\text { - Rales on lung auscultation }\end{array}$ \\
\hline Wang et al.,30 (2020) & Case report & $\begin{array}{l}1 \text { pregnant woman; } \\
1 \text { neonate }\end{array}$ & China & - Fever \\
\hline Wang et al.,31 (2020) & Case report & $\begin{array}{l}1 \text { pregnant woman; } \\
1 \text { neonate }\end{array}$ & China & $\begin{array}{l}\text { - Fever; } \\
\text { - Little rhonchi over the left lower lung field (Lung auscultation); } \\
\text { - Severe atypical pneumonia }\end{array}$ \\
\hline Wu et al..,9 (2020) & $\begin{array}{l}\text { Retrospective case } \\
\text { review }\end{array}$ & $\begin{array}{l}23 \text { pregnant women; } \\
21 \text { neonates }\end{array}$ & China & $\begin{array}{l}\text { - Fever }(n=4) \\
\text { - Cough }(n=6) \\
\text { - Nasal congestion }(n=1)\end{array}$ \\
\hline Xia et al.,32 (2020) & Case report & $\begin{array}{l}1 \text { pregnant woman; } \\
1 \text { neonate }\end{array}$ & China & $\begin{array}{l}\text { - Fever; } \\
\text { - Reduced fetal movement }\end{array}$ \\
\hline Yan et al.,33 (2020) & $\begin{array}{l}\text { Retrospective case } \\
\text { review }\end{array}$ & $\begin{array}{l}116 \text { pregnant women; } \\
84 \text { neonates }\end{array}$ & China & $\begin{array}{l}\text { - Fever }(n=50) \\
\text { - Cough }(n=27) \\
\text { - Fatigue }(n=15) ; \\
\text { - Dyspnea }(n=10) ; \\
\text { - Sore throat }(n=8) ; \\
\text { - Myalgia }(n=6) ; \\
\text { - Diarrhea }(n=1)\end{array}$ \\
\hline
\end{tabular}


Description of pregnant women's clinical characteristics in the selected studies.

\begin{tabular}{|c|c|c|c|c|}
\hline Author (year) & Study design & Participants & Location & Clinical features of pregnant women \\
\hline Yu et al.,34 (2020) & $\begin{array}{l}\text { Retrospective case } \\
\text { review }\end{array}$ & $\begin{array}{l}7 \text { pregnant women; } \\
7 \text { neonates }\end{array}$ & China & $\begin{array}{l}\text { - Uterine scarring }(n=3) ; \\
\text { - Abdominal pain }(n=4) ; \\
\text { - Increased fetal movement }(n=1) \text {; } \\
\text { - Cough }(n=1) ; \\
\text { - Fever }(n=6) ; \\
\text { - Diarrhea }(n=1) \\
\text { - H1N1 }(n=2)\end{array}$ \\
\hline Zamaniyan et al.,35 (2020) & Case report & $\begin{array}{l}1 \text { pregnant woman; } \\
1 \text { neonate }\end{array}$ & Iran & $\begin{array}{l}\text { - Fever; } \\
\text { - Cough; } \\
\text { - Dyspnea; } \\
\text { - Myalgia; } \\
\text { - Gastrointestinal symptoms; } \\
\text { - Respiratory distress; } \\
\text { - ARDS }\end{array}$ \\
\hline Zambrano et al.,36 (2020) & Case report & $\begin{array}{l}1 \text { pregnant woman; } \\
1 \text { neonate }\end{array}$ & Honduras & $\begin{array}{l}\text { - Fever; } \\
\text { - Cough; } \\
\text { - Headache; } \\
\text { - Myalgia; } \\
\text { - Bilateral conjunctival hyperemia }\end{array}$ \\
\hline Zhu et al.,5 (2020) & $\begin{array}{l}\text { Retrospective case } \\
\text { review }\end{array}$ & $\begin{array}{l}9 \text { pregnant women; } \\
10 \text { neonates }\end{array}$ & China & $\begin{array}{l}\text { - Fever, associated or not with a cough }(n=8) \\
\text { - Cholecystitis }(n=1) \\
\text { - Diarrhea }(n=1)\end{array}$ \\
\hline
\end{tabular}


Description of pregnant women's laboratorial data and radiological characteristics in selected studies.

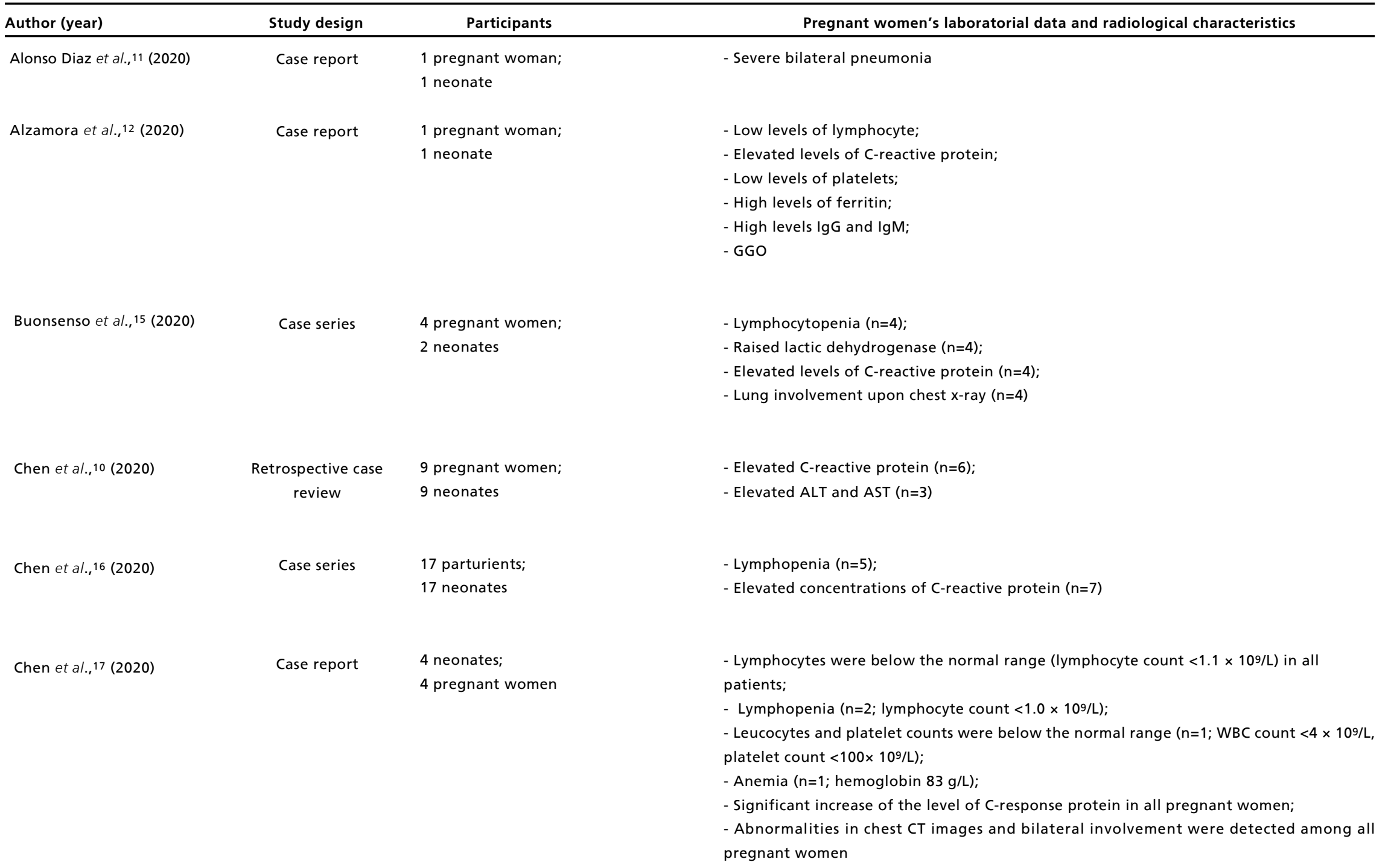

pregnant women 
Description of pregnant women's laboratorial data and radiological characteristics in selected studies.

\begin{tabular}{|c|c|c|c|}
\hline Author (year) & Study design & Participants & Pregnant women's laboratorial data and radiological characteristics \\
\hline Fan et al.,18 (2020) & Case series & $\begin{array}{l}2 \text { pregnant physicians; } \\
2 \text { neonates }\end{array}$ & - Lymphopenia $(n=2)$ \\
\hline Ferrazzi et al.,12 (2020) & $\begin{array}{l}\text { Retrospective case } \\
\text { review }\end{array}$ & $\begin{array}{l}42 \text { pregnant women; } \\
42 \text { neonates }\end{array}$ & $\begin{array}{l}\text { - High leukocyte count }(n=16) ; \\
\text { - Lymphopenia }(n=6) ; \\
\text { - Elevated C-reactive protein }(n=17) ; \\
\text { - Elevated ALT or AST }(n=5)\end{array}$ \\
\hline Gidlöf et al.,19 (2020) & Case report & $\begin{array}{l}1 \text { pregnant woman; } \\
2 \text { neonates }\end{array}$ & $\begin{array}{l}\text { - Proteinuria; } \\
\text { - Chest CT ruled out pulmonary embolism, but with typical signs of COVID-19 pneumonia }\end{array}$ \\
\hline Gonzáles Romero et al.,20 (2020) & Case report & $\begin{array}{l}1 \text { pregnant woman; } \\
1 \text { neonate }\end{array}$ & $\begin{array}{l}\text { - Low levels of lymphocyte; } \\
\text { - Elevated C-reactive protein; } \\
\text { - Elevated ALT and AST; } \\
\text { - Elevated D-dimmer; } \\
\text { - Alterations upon chest x-ray }\end{array}$ \\
\hline Hantoushzadeh et al.,21 (2020) & Case report & $\begin{array}{l}9 \text { pregnant women; } \\
7 \text { neonates }\end{array}$ & $\begin{array}{l}\text { - Low levels of leukocyte }(n=5) \text {; } \\
\text { - Low level of lymphocyte }(n=8) \text {; } \\
\text { - Elevated levels of C-reactive protein }(n=9) \text {; } \\
\text { - Elevated levels of ALT and AST }(n=6) ; \\
\text { - Low levels of platelets }(n=2) ; \\
\text { - GGO }(n=9)\end{array}$ \\
\hline
\end{tabular}


Description of pregnant women's laboratorial data and radiological characteristics in selected studies.

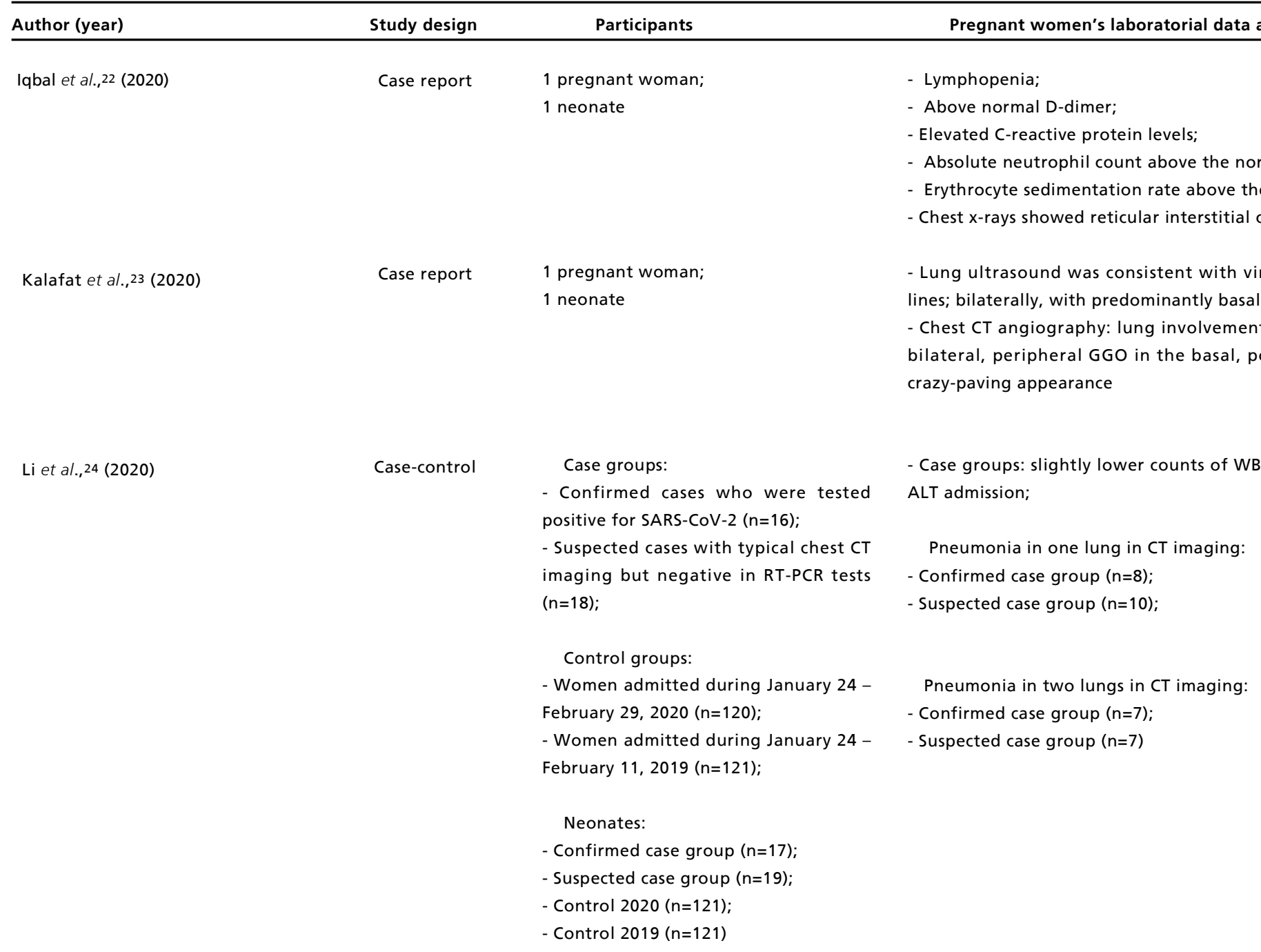

- Control $2019(n=121)$ 
Table 2

continuation

Description of pregnant women's laboratorial data and radiological characteristics in selected studies.

\begin{tabular}{lcll}
\hline Author (year) & Study design & Participants & Pregnant women's laboratorial data and radiological characteristics \\
\hline Li et $a l ., 25(2020)$ & Case report & $\begin{array}{l}1 \text { pregnant woman; } \\
1 \text { neonate }\end{array}$ &
\end{tabular}

Liu et $a l ., 26(2020)$

Liu et al.,27 (2020)
Retrospective case

review

\section{5 pregnant women;}

11 neonates

Clinical research

\section{- 41 pregnant women*;}

-11 non-pregnant adults;

* 16 pregnant women were SARS-CoV-2 positive;

17 tested -negative but with typical CT

features of COVID-19 pneumonia; and

the other 8 did not undergo SARS-CoV-

2 test

- Low lymphocyte count $(n=12)$;

- Increased C-reactive protein value $(n=10)$

- Leukocytosis and elevated neutrophil ratio were more frequent inpregnant women ( $n=8 / 16$ and 9/25);

- Lymphopenia ( $n=9 / 16$ and $16 / 25)$;

- Decreased lymphocyte ratio $(n=16 / 16$ and $22 / 25)$

- Elevated C-reactive protein ( $n=13 / 16$ and 14/25);

- Pleural effusion was identified in patients in the laboratorial-confirmation $(n=6 / 16)$ and clinically-diagnosed pregnant groups $(n=6 / 25)$ 
Description of pregnant women's laboratorial data and radiological characteristics in selected studies.

\begin{tabular}{|c|c|c|c|}
\hline Author (year) & Study design & Participants & Pregnant women's laboratorial data and radiological characteristics \\
\hline Wu et al.,9 (2020) & $\begin{array}{c}\text { Retrospective case } \\
\text { review }\end{array}$ & $\begin{array}{l}23 \text { pregnant women; } \\
21 \text { neonates }\end{array}$ & $\begin{array}{l}\text { - CT images alterations }(n=23) \\
\text { - GGO }(n=23) \\
\text { - Single lung lobe }(n=9) \\
\text { - Multiples lung lobe }(n=14)\end{array}$ \\
\hline Xia et al.,32 (2020) & Case report & $\begin{array}{l}1 \text { pregnant woman; } \\
1 \text { neonate }\end{array}$ & $\begin{array}{l}\text { - Neutrophils } 4.48\left(\times 10^{9} \mathrm{~L}-1\right) \\
\text { - Lymphocytes } 0.74 \mathrm{~g} \mathrm{~L}^{-1} ; \\
\text { - C-reactive protein } 99.6 \mathrm{mg} \mathrm{L}-1\end{array}$ \\
\hline Yan et al.,33 (2020) & $\begin{array}{c}\text { Retrospective case } \\
\text { review }\end{array}$ & $\begin{array}{l}116 \text { pregnant women; } \\
84 \text { neonates }\end{array}$ & $\begin{array}{l}\text { - Low levels of leukocyte }(n=96) \\
\text { - Low levels of lymphocytes }(n=42) \\
\text { - Elevated levels of C-reactive protein }(n=36) \\
\text { - GGO }(n=88)\end{array}$ \\
\hline Yu et al., 34 (2020) & $\begin{array}{c}\text { Retrospective case } \\
\text { review }\end{array}$ & $\begin{array}{l}7 \text { pregnant women; } \\
7 \text { neonates }\end{array}$ & $\begin{array}{l}\text { - Neutrophil levels above the normal range }(n=5) \text {; } \\
\text { - Decreased lymphocytes }(n=5) \text {; } \\
\text { - Decreased platelets }(n=2) ; \\
\text { - D-dimer above normal }(n=7) ; \\
\text { - Liver function abnormality }(n=2) ; \\
\text { - Increased ALT or AST, or both }(n=2) ; \\
\text { - Regarding infection-related biomarkers, procalcitonin (measured in six patients) } \\
\text { and erythrocyte sedimentation rate (measured in five patients) were above the } \\
\text { normal ranges ( } n=4) \text {; } \\
\text { - High concentrations of c-reactive protein }(n=7) ; \\
\text { - Interleukin- } 6 \text { was tested in four patients, all of whom had levels above the } \\
\text { normal range; } \\
\text { - Legionella pneumophila co-infections }(n=1) ; \\
\text { - Bilateral pneumonia according to chest CT }(n=6) ; \\
\text { - Unilateral pneumonia according to chest CT }(n=1)\end{array}$ \\
\hline
\end{tabular}


Description of pregnant women's laboratorial data and radiological characteristics in selected studies.

\section{Author (year)}

Zamaniyan et al.,35 (2020)

Zhu et al.,5 (2020)

Retrospective case

review

9 pregnant women

10 neonates

Pregnant women's laboratorial data and radiological characteristics

Low levels of leukocyte:

Low levels of lymphocytes

- Elevated levels of C-reactive protein;

Chest CT: Left-sided atelectasis in inferior zone:

- Bilateral GGO

Changes typical of viral pneumonia in chest CT: decreased diffuse and bilateral GGO, patchy lung consolidation, and blurred borders; when the disease progressed, the lesions merged into strips (all patients) 


\begin{tabular}{|c|c|c|c|c|c|}
\hline Author (year) & Study design & Participants & Childbirth & Characteristics of the babies at birth & Vertical transmission \\
\hline Alonso Diaz et al.,11 (2020) & Case report & $\begin{array}{l}1 \text { pregnant woman; } \\
1 \text { neonate }\end{array}$ & - Cesarean section & $\begin{array}{l}\text { - Low birthweight; } \\
\text { - Respiratory distress; } \\
\text { - Intermittent hyperpnoea; } \\
\text { - Oxygen desaturation; } \\
\text { - Mild blood acidosis; } \\
\text { - GGO }\end{array}$ & $\begin{array}{l}\text { Inconclusive } \\
\text { (Baby tested positive for SARS-CoV-2, but it had } \\
\text { direct contact with mother) }\end{array}$ \\
\hline Alzamora et al.,12 (2020) & Case report & $\begin{array}{l}1 \text { pregnant woman; } \\
1 \text { neonate }\end{array}$ & $\begin{array}{l}\text { - Cesarean section } \\
\text { - Pre-term }\end{array}$ & $\begin{array}{l}\text {-Prematurity; } \\
\text { - Respiratory difficulty; } \\
\text { - Cough }\end{array}$ & $\begin{array}{l}\text { Likely } \\
\text { (Baby tested positive for SARS-CoV-2 and it did not } \\
\text { have direct contact with mother. But amniotic fluid, } \\
\text { placenta and cord blood were not tested) }\end{array}$ \\
\hline Breslin et al.,13 (2020) & Case series & $\begin{array}{l}29 \text { pregnant women } \\
\text { with symptomatic } \\
\text { admitted; } \\
14 \text { pregnant women } \\
\text { asymptomatic } \\
\text { admitted }\end{array}$ & $\begin{array}{l}\text { - Cesarean section } \\
(\mathrm{n}=8) ; \\
- \text { Vaginal delivery } \\
(\mathrm{n}=10) ; \\
\text { - Pre-term }(\mathrm{n}=1)\end{array}$ & $\begin{array}{l}\text { - Prematurity }(n=1) \\
\text { - Congenitally diagnosed multi-cystic } \\
\text { dysplastic kidney after delivery }(n=1) \\
\text { - Respiratory distress }(n=1)\end{array}$ & $\begin{array}{l}\text { No evidence of } V T \\
\text { (all babies tested negative by nasopharyngeal swab) }\end{array}$ \\
\hline Breslin et al., 14 (2020) & Case series & 7 pregnant women & $\begin{array}{l}\text { - Cesarean section } \\
(n=2)\end{array}$ & - Not informed & Not informed \\
\hline Buonsenso et al.,15 (2020) & Case series & $\begin{array}{l}4 \text { pregnant women; } \\
2 \text { neonates }\end{array}$ & $\begin{array}{l}\text { - Cesarean section } \\
(\mathrm{n}=2)\end{array}$ & - No alteration informed & $\begin{array}{l}\text { No evidence of VT } \\
\text { (Babies were tested negative. Cord blood was tested } \\
\text { negative) }\end{array}$ \\
\hline
\end{tabular}


Description of childbirth, babies' characteristics at birth and vertical transmission in selected studies.

\begin{tabular}{llll}
\hline Author (year) & Study design & Participants & \multicolumn{1}{c}{ Childbirth } \\
\hline \multirow{2}{*}{ Chen et al.,10 (2020) } & Retrospective case & 9 pregnant women; & - Cesarean section \\
review & 9 neonates & $(n=8) ;$ \\
& & - Emergency cesarean \\
& & section $(n=1) ;$ \\
& - Gestational age at \\
& birth: $36-39$ weeks + \\
& 4 days; \\
& & - Fetal distress $(n=2) ;$ \\
& - Preterm birth $(n=4) ;$ \\
& - PROM $(n=2)$
\end{tabular}

\section{Characteristics of the babies at birth $\quad$ Vertical transmission}

Prematurity $(n=4)$ Inconclusive

- Birthweight lower than $2,500 \mathrm{~g}$ (one baby diagnosed with SARS-CoV-2 $36 \mathrm{~h}$ after $(n=2)$; birth, even after being isolated from the mother. - Mild increase in myocardial Nevertheless, placenta, cord blood and amniotic enzymes $(n=1)$

fluid were negative for the virus)

PROM $(n=2)$

\begin{tabular}{|c|c|c|c|c|}
\hline Chen et al.,16 (2020) & Case series & $\begin{array}{l}17 \text { parturients; } \\
17 \text { neonates }\end{array}$ & $\begin{array}{l}\text { - Cesarean section } \\
(n=14) ; \\
\text { - Emergency cesarean } \\
\text { section }(n=3)\end{array}$ & $\begin{array}{l}\text { - Premature birth with normal } \\
\text { weight }(n=3)\end{array}$ \\
\hline Chen et al.,17 (2020) & Case report & $\begin{array}{l}4 \text { neonates; } \\
4 \text { pregnant women }\end{array}$ & $\begin{array}{l}\text { - Cesarean section in } \\
\text { the acute phase of } \\
\text { the disease }(n=3) ; \\
\text { - Vaginal delivery } \\
(n=1) ; \\
\text { - All babies were } \\
\text { born beyond } 37 \\
\text { weeks' gestation and } \\
\text { with birthweight } \\
\text { above } 3,000 \mathrm{~g}\end{array}$ & $\begin{array}{l}\text { - Negative for COVID-19 }(n=3) \text {. One } \\
\text { baby's parents did not provide } \\
\text { consent for their baby to be tested } \\
\text { for COVID-19; } \\
\text { - Rashes of unknown etiology at } \\
\text { birth }(n=2) \text {; } \\
\text { - Facial ulcerations }(n=1) \text {; } \\
\text { - Tachypnea }(n=1) \text {; } \\
\text { - Edema of the lateral thigh and } \\
\text { low level of serum albumin }(n=1)\end{array}$ \\
\hline
\end{tabular}

VT= Vertical transmission; PROM= Premature Rupture of Membranes; ICU= Intensive Care Unit; SGA= Small-for-gestational-age; PCIS= Pediatric Critical IIIness Score; NRDS= Neonatal 
Description of childbirth, babies' characteristics at birth and vertical transmission in selected studies.

\begin{tabular}{|c|c|c|c|c|c|}
\hline Author (year) & Study design & Participants & Childbirth & Characteristics of the babies at birth & Vertical transmission \\
\hline Fan et al.,18 (2020) & Case series & $\begin{array}{l}2 \text { pregnant physicians; } \\
2 \text { neonates }\end{array}$ & $\begin{array}{l}\text { - Cesarean section } \\
\text { ( } 37 \text { weeks and } 36 \\
\text { weeks and } 5 \text { days) } \\
(n=2) ; \\
\text { - Preterm }(n=1)\end{array}$ & $\begin{array}{l}\text { - Prematurity with normal weight } \\
(n=1) \text {; } \\
\text { - Pneumonia }(n=1) \text {; } \\
\text { - Lymphopenia }(n=2) ; \\
\text { - Low-grade fever }(n=1) \text {; } \\
\text { - Abdominal distension }(n=1)\end{array}$ & $\begin{array}{l}\text { No evidence of VT } \\
\text { (no babies tested positive for SARS-CoV-2. Baby's } \\
\text { nasopharyngeal swab, and maternal serum, } \\
\text { placenta tissue, umbilical cord blood, amniotic } \\
\text { fluid, vaginal swabs and breast milk were tested) }\end{array}$ \\
\hline Ferrazzi et al.,8 (2020) & $\begin{array}{c}\text { Retrospective } \\
\text { case review }\end{array}$ & $\begin{array}{l}42 \text { pregnant women; } \\
42 \text { neonates }\end{array}$ & $\begin{array}{l}\text { - Elective cesarean } \\
\text { section for } \\
\text { conditions } \\
\text { determined by } \\
\text { COVID-19 }(n=10) ; \\
\text { - Elective cesarean } \\
\text { section for reasons } \\
\text { unrelated with } \\
\text { COVID-19 }(n=8) ; \\
\text { - Vaginal delivery } \\
\text { ( } n=24) ; \\
\text { - Pre-term }(n=11)\end{array}$ & $\begin{array}{l}\text { - Prematurity }(n=11) \\
\text { - Respiratory symptoms }(n=1) \\
\text { - Gastrointestinal symptoms }(n=1)\end{array}$ & $\begin{array}{l}\text { Inconclusive } \\
\text { ( } 3 \text { babies tested positive for SARS-CoV-2 through } \\
\text { throat swab tested by RT-PCR) }\end{array}$ \\
\hline Gidlöf et al.,19 (2020) & Case report & $\begin{array}{l}1 \text { pregnant woman; } \\
2 \text { neonates }\end{array}$ & $\begin{array}{l}\text { - Emergency } \\
\text { cesarean section; } \\
\text { - Pre-term }\end{array}$ & $\begin{array}{l}\text { - Prematurity; } \\
\text { - Twin } 1 \text { had a birthweight of } 2,680 \mathrm{~g} \text {. } \\
\text { At } 22 \text { minutes after childbirth it } \\
\text { developed breathing problems. Twin } \\
2 \text { had a birthweight of } 2,160 \mathrm{~g}\end{array}$ & $\begin{array}{l}\text { No evidence of VT } \\
\text { (Both twins had negative nasopharyngeal Covid } \\
19 \text { tests taken at } 34 \text { hours; and } 4 \frac{1}{2} \text { days of age) }\end{array}$ \\
\hline
\end{tabular}


Description of childbirth, babies' characteristics at birth and vertical transmission in selected studies..

\begin{tabular}{|c|c|c|c|c|c|}
\hline Author (year) & Study design & Participants & Childbirth & Characteristics of the babies at birth & Vertical transmission \\
\hline $\begin{array}{l}\text { Gonzáles Romero et al.,20 } \\
(2020)\end{array}$ & Case report & $\begin{array}{l}1 \text { pregnant woman; } \\
1 \text { neonate }\end{array}$ & $\begin{array}{l}\text { - Cesarean section; } \\
\text { - Pre-term }\end{array}$ & $\begin{array}{l}\text { - Prematurity; } \\
\text { - Low birthweight }\end{array}$ & $\begin{array}{l}\text { Not informed } \\
\text { (Baby untested for SARS-CoV-2) }\end{array}$ \\
\hline
\end{tabular}

Hantoushzadeh et al.,2

(2020)

Retrospective cas

review

9 pregnant women
7 neonates

$(n=6)$

- Vaginal

$(n=1)$;

- Pre-term $(n=5)$

- Low birthweight $(n=4)$

- Neonatal pneumonia $(n=1)$

- Neonatal mortality ( $n=4$; twin

pregnancy)

lqbal et al.,22 (2020)

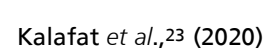

\section{No evidence of VT}

(One was tested positive for SARS-CoV-2 after 7

days of live through nasopharyngeal swab test)

Not evidence of $\mathrm{VT}$

(no evidence of neonatal or intraamniotic

infection)

\section{No evidence of VT}

(neonatal swabs, cord blood, and placental swab RT-PCR tests were negative for SARS-CoV-2) 
Description of childbirth, babies' characteristics at birth and vertical transmission in selected studies..

\begin{tabular}{|c|c|c|c|c|c|}
\hline Author (year) & Study design & Participants & Childbirth & Characteristics of the babies at birth & Vertical transmission \\
\hline Li et al.,24 (2020) & Case-control & $\begin{array}{l}\text { Case groups: } \\
\text { - Confirmed cases who } \\
\text { were tested positive } \\
\text { for SARS-CoV-2 }(n=16) ; \\
\text { - Suspected cases with } \\
\text { typical chest CT } \\
\text { imaging but negative } \\
\text { in RT-PCR tests ( } n=18) ; \\
\text { Control groups: } \\
\text { - Women admitted } \\
\text { during January } 24- \\
\text { February } 29,2020 \\
\text { (n=120); } \\
\text { - Women admitted } \\
\text { during January } 24- \\
\text { February } 11,2019 \\
\text { (n=121); } \\
\quad \text { Neonates: } \\
\text { - Confirmed case } \\
\text { group ( } n=17) ; \\
- \text { Suspected case group } \\
\text { (n=19); } \\
\text { - Control 2020 } \\
\text { (n=121); } \\
\text { - Control 2019 ( } n=121)\end{array}$ & $\begin{array}{l}\text { - Gestational weeks on } \\
\text { admission ranged: } \\
33+6 \text { to } 40+4 ; \\
\text { Cesarean section: } \\
\text { - Confirmed case group }(n=14) ; \\
\text { - Suspected case group }(n=16) ; \\
\text { - Control } 2020(n=57) ; \\
\text { - Control } 2019(n=44) ; \\
\text { Pre-term: } \\
\text { - Confirmed case group }(n=3) ; \\
\text { - Suspected case group }(n=3) ; \\
\text { - Control } 2020(n=7) ; \\
\text { - Control } 2019(n=6) ; \\
\text { Fetal distress: } \\
\text { - Confirmed case group }(n=2) ; \\
\text { - Suspected case group }(n=1) ; \\
\text { - Control } 2020(n=6) ; \\
\text { - Control } 2019(n=6) ; \\
\text { PRoM and placental abruption: } \\
\text { - Confirmed case group }(n=2) ; \\
\text { - Suspected case group }(n=0) ; \\
\text { - Control } 2020(n=0) ; \\
\text { - Control } 2019(n=0)\end{array}$ & $\begin{array}{l}\text { Prematurity: } \\
\text { - Confirmed case group }(n=4) ; \\
\text { - Suspected case group }(n=4) ; \\
\text { - Control } 2020(n=7) ; \\
\text { - Control } 2019(n=6) ; \\
\\
\text { Low birthweight: } \\
\text { - Confirmed case group }(n=3) ; \\
\text { - Suspected case group }(n=2) ; \\
\text { - Control } 2020(n=3) ; \\
\text { - Control } 2019(n=3)\end{array}$ & $\begin{array}{l}\text { No evidence of } \mathrm{VT} \\
\text { (all of them tested negative for SARS- } \\
\text { CoV-2) }\end{array}$ \\
\hline
\end{tabular}


Description of childbirth, babies' characteristics at birth and vertical transmission in selected studies.

\begin{tabular}{|c|c|c|c|c|c|}
\hline Author (year) & Study design & Participants & Childbirth & Characteristics of the babies at birth & Vertical transmission \\
\hline Li et al.,.25 (2020) & Case report & $\begin{array}{l}1 \text { pregnant woman; } \\
1 \text { neonate }\end{array}$ & $\begin{array}{l}\text { - Emergency } \\
\text { cesarean section in } \\
\text { the } 35^{\text {th }} \text { gestational } \\
\text { week (pre-term); } \\
\text { - No complications } \\
\text { during delivery }\end{array}$ & $\begin{array}{l}\text { - Prematurity; } \\
\text { - Fetal heart rate monitor showed } \\
110 \text { beats/min that resulted in } \\
\text { medical decision for emergency } \\
\text { cesarean section; } \\
\text { - baby was negative for SARS-CoV-2 } \\
\text { immediately after he was taken from } \\
\text { the uterus and after } 2 \text { days }\end{array}$ & $\begin{array}{l}\text { No evidence of VT } \\
\text { (Baby tested negative for SARS-CoV-2. Urine, } \\
\text { feces, amniotic fluid, umbilical cord blood, } \\
\text { placenta and breast milk were tested) }\end{array}$ \\
\hline Liu et al.,26 (2020) & $\begin{array}{l}\text { Retrospective } \\
\text { case review }\end{array}$ & $\begin{array}{l}15 \text { pregnant women; } \\
11 \text { neonates }\end{array}$ & $\begin{array}{l}\text { - Cesarean section } \\
(n=10) ; \\
\text { - Vaginal delivery } \\
(n=1) ; \\
\text { - Delivery time } \\
\text { ranged from } 34 \\
\text { to } 38 \text { gestational } \\
\text { weeks }\end{array}$ & Not informed & $\begin{array}{l}\text { No evidence of VT } \\
\text { (no babies tested positive for SARS-CoV-2) }\end{array}$ \\
\hline Liu et al.,27 (2020) & Clinical research & $\begin{array}{l}\text { - } 41 \text { pregnant } \\
\text { women*; } \\
-11 \text { non-pregnant } \\
\text { adults; } \\
\text { *16 pregnant } \\
\text { women were SARS- } \\
\text { CoV-2 positive; } \\
17 \text { laboratory- } \\
\text { negative but with } \\
\text { typical CT features } \\
\text { of COVID-19 } \\
\text { pneumonia; and the } \\
\text { other } 8 \text { did not } \\
\text { undergo SARS-CoV-2 } \\
\text { test }\end{array}$ & $\begin{array}{l}\text { - Gestational age } \\
\text { ranged from } 22 \\
\text { weeks to } 40 \text { weeks } \\
+5 \text { days }\end{array}$ & Not informed & Not informed \\
\hline
\end{tabular}

VT= Vertical transmission: PROM= Premature Rupture of Membranes: ICU=Intensive Care Unit: SGA= Small-for-gestational-age; PCIS= Pediatric Critical IIIness SCore: NRDS= Neonata Respiratory Distress Syndrome; DiC 
Description of childbirth, babies' characteristics at birth and vertical transmission in selected studies.

\begin{tabular}{|c|c|c|c|c|c|}
\hline Author (year) & Study design & Participants & Childbirth & Characteristics of the babies at birth & Vertical transmission \\
\hline Liu et al.,28 (2020) & $\begin{array}{l}\text { Retrospective } \\
\text { case review }\end{array}$ & $\begin{array}{l}13 \text { pregnant women; } \\
13 \text { neonates }\end{array}$ & $\begin{array}{l}\text { - } 3 \text { patients } \\
\text { improved after } \\
\text { hospitalization and } \\
\text { got discharged } \\
\text { with an } \\
\text { uncomplicated } \\
\text { ongoing } \\
\text { pregnancy; } \\
\text { - Cesarean section } \\
\text { in } 10 \text { patients, } \\
\text { being emergency } \\
\text { cesarean section in } \\
5 \text { patients due to } \\
\text { complications; } \\
\text { - Fetal distress } \\
\text { ( } n=3 \text { ); } \\
\text { - PROM ( } n=1) \text {; } \\
\text { - Stillbirth ( } n=1 \text {; } \\
\text { - Preterm labor } \\
\text { between } 32-36 \\
\text { weeks of gestation } \\
(n=6)\end{array}$ & $\begin{array}{l}\text { - Prematurity }(n=6) \\
\text { - Death }(n=1)\end{array}$ & $\begin{array}{l}\text { No evidence of VT } \\
\text { (no babies tested positive for SARS-CoV-2) }\end{array}$ \\
\hline Song et al.,29 (2020) & Case report & $\begin{array}{l}1 \text { pregnant woman; } \\
1 \text { neonate }\end{array}$ & $\begin{array}{l}\text { - Emergency } \\
\text { cesarean section } \\
\text { (36 weeks and } 3 \\
\text { days); } \\
\text { - Preterm }\end{array}$ & $\begin{array}{l}\text { - Prematurity with normal weight } \\
(3.63 \mathrm{~kg})\end{array}$ & $\begin{array}{l}\text { No evidence of VT } \\
\text { (Baby did not test positive for SARS-CoV-2) }\end{array}$ \\
\hline Wang et al.,30 (2020) & Case report & $\begin{array}{l}1 \text { pregnant woman; } \\
1 \text { neonate }\end{array}$ & $\begin{array}{l}\text { - Cesarean section } \\
\text { (40 weeks) }\end{array}$ & $\begin{array}{l}\text { - Lymphopenia; } \\
\text { - Deranged liver } \\
\text { function tests; } \\
\text { - Elevated total and indirect bilirubin; } \\
\text { - Elevated creatine kinase level }\end{array}$ & $\begin{array}{l}\text { Inconclusive } \\
\text { (Baby tested positive for SARS-CoV-2. Cord blood, } \\
\text { placental specimens and breast milk were tested) }\end{array}$ \\
\hline
\end{tabular}

VT= Vertical transmission; PROM= Premature Rupture of Membranes; ICU= Intensive Care Unit; SGA= Small-for-gestational-age; PCIS= Pediatric Critical IIIness Score; NRDS= Neonata Respiratory Distress Syndrome; DIC= Disseminate Intravascular Coagulation. 


\begin{tabular}{|c|c|c|c|c|c|}
\hline Author (year) & Study design & Participants & Childbirth & Characteristics of the babies at birth & Vertical transmission \\
\hline Wang et al.,31 (2020) & Case report & $\begin{array}{l}1 \text { pregnant woman; } \\
1 \text { neonate }\end{array}$ & $\begin{array}{l}\text { - Emergency } \\
\text { cesarean section } \\
\text { during the 30th } \\
\text { gestational week; } \\
\text { - Preterm }\end{array}$ & $\begin{array}{l}\text { - No fetal movement and no } \\
\text { variability of fetal heart rate; } \\
\text { - Prematurity; } \\
\text { - Low birthweight }(1.83 \mathrm{~kg}) \text {; } \\
\text { - Kept in isolation ICU for } \\
\text { observation; } \\
\text { - Baby had an uneventful neonatal } \\
\text { course }\end{array}$ & $\begin{array}{l}\text { No evidence of VT } \\
\text { (Baby did not test positive for SARS-CoV- } 2 \text {. } \\
\text { Amniotic fluid, placenta, umbilical cord blood, } \\
\text { gastric juice and throat swabs were tested) }\end{array}$ \\
\hline Wu et al., ${ }^{9}(2020)$ & $\begin{array}{l}\text { Retrospective } \\
\text { case review }\end{array}$ & $\begin{array}{l}23 \text { pregnant women; } \\
21 \text { neonates }\end{array}$ & $\begin{array}{l}\text { - Cesarean section } \\
(n=18) \\
\text { - Vaginal delivery } \\
(n=2)\end{array}$ & Not informed & $\begin{array}{l}\text { No evidence of VT } \\
\text { ( } 4 \text { babies tested negative for SARS-CoV-2 RT-PCR. } \\
\text { Others were not tested) }\end{array}$ \\
\hline Xia et al.,32 (2020) & Case report & $\begin{array}{l}1 \text { pregnant woman; } \\
1 \text { neonate }\end{array}$ & $\begin{array}{l}\text { - Emergency } \\
\text { cesarean section } \\
\text { ( } 37 \text { weeks and } 2 \\
\text { days) }\end{array}$ & Not informed & $\begin{array}{l}\text { No evidence of } \mathrm{VT} \\
\text { (Baby did not test positive for SARS-CoV-2) }\end{array}$ \\
\hline Yan et al.,33 (2020) & $\begin{array}{l}\text { Retrospective } \\
\text { case review }\end{array}$ & $\begin{array}{l}116 \text { pregnant } \\
\text { women } \\
84 \text { neonates }\end{array}$ & $\begin{array}{l}\text { - Cesarean section } \\
(n=85) ; \\
\text { - Vaginal delivery } \\
(n=14) ; \\
\text { - Pre-term }(n=23) ; \\
\text { - Fetal distress } \\
(n=9) ; \\
\text { - Abnormal } \\
\text { placenta (placenta } \\
\text { previa) }(n=3) ; \\
\text { - Abnormal fetal } \\
\text { growth }(n=2)\end{array}$ & $\begin{array}{l}\text { - Prematurity }(n=23) \\
\text { - Low birthweight }(n=8) \\
\text { - Death }(n=1)\end{array}$ & $\begin{array}{l}\text { No evidence of VT } \\
\text { (Baby did not test positive for SARS-CoV-2. Cord } \\
\text { blood, amniotic fluid, vagina mucus and breast } \\
\text { milk were tested) }\end{array}$ \\
\hline
\end{tabular}

VT= Vertical transmission; PROM= Premature Rupture of Membranes; ICU= Intensive Care Unit; SGA= Small-for-gestational-age; PCIS= Pediatric Critical IIIness Score; NRDS= Neonata N Respiratory Distress Syndrome; DIC= Disseminate Intravascular Coagulation. 
Description of childbirth, babies' characteristics at birth and vertical transmission in selected studies..

\begin{tabular}{lcclll}
\hline Author (year) & Study design & Participants & Childbirth & Characteristics of the babies at birth & Vertical transmission \\
\hline Yu et al.,34 (2020) & Retrospective & 7 pregnant women; & - Cesarean section; & - Mild shortness of breath & Inconclusive \\
& case review & 7 neonates & - Delivery time ranged & symptoms. & (one baby diagnosed with SARS-CoV-2 36h after \\
& & & from 37 weeks to 41 & - Chest $\mathrm{x}$-ray revealed mild & birth, but placenta and cord blood were negative \\
& & & weeks plus 2 days & pulmonary infection ( $\mathrm{n}=1)$ & for virus)
\end{tabular}

1 pregnant woman;

$$
1 \text { neonate }
$$

- Cesarean section

- Pre-term
- Prematurity;
- Low birthweight
- Fever

Likely

(Baby was tested positive for SARS-CoV-2 and it did not have direct contact with mother. Amniotic fluid tested positive for SARS-CoV-2)

\section{No evidence of VT}

(nasopharyngeal and blood samples tested by SARS-CoV-2 RT-PCR were negative) and multicystic right

kidney;

- Pre-term;

- Vaginal delivery 
Description of childbirth, babies' characteristics at birth and vertical transmission in selected studies.

\begin{tabular}{|c|c|c|c|c|c|}
\hline Author (year) & Study design & Participants & Childbirth & Characteristics of the babies at birth & Vertical transmission \\
\hline Zhu et al.,5 (2020) & $\begin{array}{l}\text { Retrospective } \\
\text { case review }\end{array}$ & $\begin{array}{l}9 \text { pregnant women; } \\
10 \text { neonates }\end{array}$ & $\begin{array}{l}\text { - Cesarean section } \\
(n=7) ; \\
\text { - Vaginal delivery } \\
(n=2) ; \\
\text { - Pre-term }(n=6) ; \\
\text { - Intrauterine } \\
\text { distress }(n=6) ; \\
\text { - PROM (5 to } 7 \text { hours } \\
\text { before the onset of } \\
\text { true labor) ( } n=3) ; \\
\text { - Abnormal amniotic } \\
\text { fluid }(n=2) ; \\
\text { - Abnormal umbilical } \\
\text { cord }(n=2) ; \\
\text { - Abnormal placenta } \\
\text { (placenta previa) } \\
\text { ( } n=1)\end{array}$ & $\begin{array}{l}\text { - Prematurity ( } n=6) ; \\
\text { - SGA ( } n=2) ; \\
\text { - Large-for-gestational-age }(n=1) ; \\
\text { - PCIS score of less than } 90(n=6) ; \\
\text { - First symptom: Shortness of breath } \\
(n=6) ; \\
\text { - Fever ( } n=2) ; \\
\text { - Rapid heart rate }(n=1) ; \\
\text { - Feeding intolerance, bloating, } \\
\text { refusing milk, and gastric bleeding } \\
\text { ( } n=4) ; \\
\text { - Abnormalities in chest } x \text {-ray: } \\
\text { infectious ( } n=4), \text { NRDS ( } n=2), \text { and } \\
\text { pneumothorax ( } n=1) ; \\
\text { - Thrombocytopenia } \\
\text { complicated with abnormal liver } \\
\text { function ( } n=2) ; \\
\text { - One pre-term neonate ( } 34 \text { weeks } \\
\text { and } 5 \text { days) had shortness } \\
\text { of breath and moaning. Eight days } \\
\text { later he developed } \\
\text { refractory shock, multiple organ } \\
\text { failure, and DIC. He died on the } 9 \text { th } \\
\text { day; } \\
\text { - One preterm neonate ( } 34 \text { weeks } \\
\text { and } 6 \text { days) had shortness of breath } \\
\text { and moaning. He suffered from } \\
\text { frequent oxygenation fluctuations } \\
\text { at } 3 \text { days of age, along with poor } \\
\text { response and sharp drop in } \\
\text { platelets. He was cured } 15 \text { days } \\
\text { later }\end{array}$ & $\begin{array}{l}\text { No evidence of } \mathrm{VT} \\
\text { (no babies tested positive for SARS-CoV-2) }\end{array}$ \\
\hline
\end{tabular}

VT= Vertical transmission; PROM= Premature Rupture of Membranes; ICU=Intensive Care Unit; SGA= Small-for-gestational-age; PCIS= Pediatric Critical IIIness Score; NRDS= Neonatal Respiratory Distress Syndrome; DIC= Disseminate Intravascular Coagulation. 
be helpful to diagnose virus pneumonia. ${ }^{27}$ In their study, some patients tested by real-time reverse transcription polymerase chain reaction assay (RT-PCR) retrieved negative results and presented alterations on chest CT images, such as patchy shadows and/or ground-glass opacities. In this case, chest CT seems to have a high accuracy to diagnose SARS-CoV-2 infections and present low levels of false negative results, 9,10,13,15,19,23,33 unlike RT-PCR. In addition, relevant clinical examinations such as blood cell counts should be performed together with a comprehensive assessment of the patient's medical history, epidemiological exposure and symptoms in general.8-10,13,24,33

It is important to highlight that, despite chest CT not being frequently conducted on pregnant women due to its level of radiation, in Liu et al.27 the dose was adjusted to pregnant women to allow the acquirement of images that could present signals of viral infection. This adjustment was responsible for lower-resolution images, but the quality of these images was sufficient to diagnose viral pneumonia and other alterations, such as ground-glass opacities.

All studies included in this review diagnosed patients with SAR-CoV-2 infection by using RTPCR. However, it is important to highlight that several studies reported the possibility of a false negative result for patients who might had been infected by SARS-CoV-2.5,10,27,30,33,34 Previous evidence has argued that false negative results could have happened due to insufficient viral load, sampling at early or late stage of the illness, and inappropriate swabbing sites. ${ }^{30}$ In Fan et al. ${ }^{18}$ study a pregnant patient was positive diagnosed with SARS-CoV-2 after two negative samplings, and Liu et al. 27 conducted several analyses in 25 pregnant women clinically-diagnosed but they had not received the laboratorial- confirmation.

Due to this uncertainty related to false negative results, almost all reviewed papers reported the election of a cesarean section ( $\mathrm{n}=239$ women $)$ for childbirth.8-21,23-26,28-36 Only 42 cases of pregnant women delivered babies vaginally were reported, 5,8,9,13,17,21,22,26,33,36 but all newborns were negative for SARS-CoV-2.

Out of the 279 neonates, 17 were delivered by an emergency cesarean section. 10,11,15,16,19,21,25,28,29,31,32 For these mothers, an emergency cesarean section was elected due to some complications such as pre-eclampsia, 19,21 gestational hypertension, 10,19 fetal bradycardia, 15 fetal distress, 5,10,16,28 PROM5,10,28 and decreased fetal movement and oxygen decompensation. 21

Previous studies have reported the pregnant women with viral pneumonia are more likely to have complications during pregnancy and can also lead to spontaneous miscarriage, preterm birth, low birth weight infants, intrauterine growth restriction and five-minute Apgar score $<7$ compared to healthy pregnant women. 38 The results of this study have evidenced a high rate of preterm births $(n=49)$, and out of 273 neonates were delivered and six deaths were reported.

Previous studies have shown that SARS-CoV-2 can be transmitted from human-to-human through close contact of the droplets and also via aerosol.1,2 However, the potential for transmissibility from mother-to-fetus is still unknown. In this review, among 279 neonates evaluated by different studies, only ten showed a positive result for SARS-CoV-2, after at least 30 hours of childbirth. 10,30,34 However, in some cases, the placenta, umbilical cord, amniotic fluid and breast milk were tested and no positive result for the presence of the virus was found. 10,18,25,30,31,34 It is important to consider the possibility of false-negative in these cases, since RTPCR method was adopted, which may have limitations due to the latency period of the virus, as previously mentioned.

Although, some authors believe that vaginal delivery may increase the risk of vertical transmission of COVID-19, the hypothesis that best explains the mother's non-viral transmission to her child was demonstrated by Zheng et al.,39 who state that the angiotensin-converting enzyme 2 (ACE2) receptor of COVID-19 has very low expression in almost all cell types of the early maternal-fetal interface, suggesting that there may be no cells that are potentially susceptible to COVID-19 in the maternal-fetal interface.

Despite still being unclear and requiring future clinical studies with a larger sample size to guarantee scientific evidence, vertical transmission seems unlikely. However, protocols for the care of pregnant women and newborns should take into account that, although studies have not shown a positive test for SARS-CoV-2 in breast milk, breastfeeding may present risks of contamination due to direct physical contact. 40 Despite this, breastfeeding should be encouraged, but mothers should be properly advised on preventive protocols to avoid transmission.

Recently, the medical field has debated about the immunization of pregnant women against SARSCoV-2, but clinical trials involving pregnant women are still scarce.41-43 A shared decision-making between the mother, her family, and the obstetrician is essential. The discussion should focus on the risks 
of infection, risk of morbidity and mortality, and the uncertainty regarding the safety of the vaccine in pregnancy and lactation. But it must be emphasized that at this point we do not have biologic reasons to believe that the currently approved vaccines are harmful to pregnant women or infants. 41,43

As well known, antibodies can be transmitted from mother to the fetus via placental transport. 44,45 The transportation of antibodies, such as Immunoglobulin-G ( $\mathrm{IgG})$, protect the baby from virus infections after birth, and this process is known as passive immunization. 44,45 However, in Wang et al., 40 the IgG levels of infants decreased considerably in the first two months of life, suggesting that the passive immunization of IgG for SARS-CoV-2 provided limited protection for the infants, especially if the mother was infected with the virus for less than two weeks before delivery.

The key question to be answered at this point is whether there is transmissibility of antibodies from the pregnant woman who received the vaccine to the fetus. Rottenstreich et al. 46 indicated that immunization of pregnant women may provide maternal and neonatal protection, since they found antibodies ( $\mathrm{IgG}$ ) in umbilical cord serum. This is still unclear, so clinical trials should be conducted to understand the association of these outcomes.

Our study has some limitations. Because of the unprecedented nature of the subject due to the recent pandemic, few population-based clinical studies have been published in the literature assessing the health condition of pregnant women and newborns relating to the involvement of COVID-19. Most of the studies included in this review were case reports and retrospective case report analyzes with a small sample size. We suggest that longitudinal clinical studies with a representative sample be conducted in order to ensure a better understanding of the relationship among COVID-19, pregnancy and neonate outcomes. Also, the percentages of each symptom during pregnancy were calculated based on a ratio between the total number of cases and the studies that have reported such condition. If a paper had not reported a determined symptom, it was inferred that that condition was not present. Moreover, most of the studies published so far have evaluated patients in the 3 rd trimester of pregnancy, which makes it impossible to understand the cause-and-effect relationship of the 1st and 2nd trimesters and COVID-19. Finally, future studies should answer some other questions, such as whether vaginal delivery increases the risk of vaginal transmissibility and whether uterine contractions increase the possibility of the virus ascending. As well as, the role of women's vaccination on infants' protection.

Despite the limitations of this study, this review carried out an extensive search of the literature in different databases, with well-defined criteria and in a standardized protocol, which ensured the inclusion of studies published in high-impact journals.

Based on this review, it can be concluded:

1- COVID-19 in women during pregnancy results in symptoms similar to those experienced by non-pregnant women when affected by the same disease. There is a high rate of asymptomatic positive cases during pregnancy. When the cases are symptomatic, the disease is revealed in its mildest form. Fever and cough are the clinical signs commonly seen in pregnancy;

2-There is still no plausible evidence suggesting vertical transmission of SARS-CoV-2 virus from mother to child. However, in this review it was possible to observe that cesarean sections have been performed more frequently. High rates of premature births also have been reported;

3- As COVID-19 maternal illness does not appear to be as severe as SARS and MERS, the high rate of cesarean section is unreasonable. Obstetricians should assess case by case in order to avoid the indication of unnecessary cesarean sections;

4- Although there is no evidence of the virus in the infected woman's breast milk, breastfeeding might lead to the baby's infection due to the close contact. Nevertheless, breastfeeding should be encouraged, but mothers should be given adequate guidance on preventive protocols to avoid transmission.

\section{Authors' contribution}

Foratori-Junior GA and Mosquim V contributed with literature search, figures, study design, data collection, data analysis, data interpretation and writing of this manuscript. Machado MAAM, Oliveira TM and Sales-Peres SHC contributed with study design, data analysis, data interpretation and writing of this manuscript. All authors approved the final version of the article. 


\section{References}

1. Huang C, Wang Y, Li X, Ren L, Zhao J, Hu Y, et al. Clinical features of patients infected with 2019 novel coronavirus in Wuhan, China. Lancet. 2020; 395 (10223): 497-506.

2. Wang D, Hu B, Hu C, Zhu F, Liu X, Zhang J, et al. Clinical characteristics of 138 hospitalized patients with 2019 nove coronavirus-infected pneumonia in Wuhan, China. JAMA. 2020; 323 (11): 1061-9.

3. Yang J, Zheng Y, Gou X, Pu K, Chen Z, Guo Q, et al. Prevalence of comorbidities in the novel Wuhan coronavirus (COVID-19) infection: a systematic review and meta-analysis. Int J Infect Dis. 2020; 94: 91-5.

4. Gagneur A, Dirson E, Audebert S, Vallet S, LegrandQuillien MC, Laurent Y, et al. Materno-fetal transmission of human coronaviruses: a prospective pilot study. Eur J Clin Microbiol Infect Dis. 2008; 27 (9): 863-6.

5. Zhu H, Wang L, Fang C, Peng S, Zhang L, Chang G, et al. Clinical analysis of 10 neonates born to mothers with 2019nCoV pneumonia. Transl Pediatr. 2020; 9 (1): 51-60.

6. Alserehi H, Wali G, Alshukairi A, Alraddadi B. Impact of Middle East Respiratory Syndrome coronavirus (MERS$\mathrm{CoV}$ ) on pregnancy and perinatal outcome. BMC Infect Dis. 2016; 16: 105

7. Chan JF, Kok KH, Zhu Z, Chu H, To KK, Yuan S, et al Genomic characterization of the 2019 novel human-pathogenic coronavirus isolated from a patient with atypical pneumonia after visiting Wuhan. Emerg Microbes Infect. 2020; 9 (1): 221-36.

8. Ferrazzi E, Frigerio L, Savasi V, Vergani P, Prefumo F, Barresi S, et al. Vaginal delivery in SARS-CoV-2 infected pregnant women in Northern Italy: a retrospective analysis. BJOG. 2020; 127 (9): 1116-21.

9. Wu X, Sun R, Chen J, Xie Y, Zhang S, Wang X. Radiological findings and clinical characteristics of pregnant women with COVID-19 pneumonia. Int J Gynaeco Obstet. 2020; 150 (1): 58-63.

10. Chen H, Guo J, Wang C, Luo F, Yu X, Zhang W, et al. Clinical characteristics and intrauterine vertical transmission potential of COVID-19 infection in nine pregnant women: a retrospective review of medical records. Lancet. 2020; 395 (10226): 809-15.

11. Alonso Díaz C, López Maestro M, Moral Pumarega MT, Flores Antón B, Pallás Alonso CR. Primer caso de infección neonatal por SARS-CoV-2 en España [First case of neonatal infection due to SARS-CoV-2 in Spain]. An Pediatr (Barc). 2020; 92 (4): 237-8.

12. Alzamora MC, Paredes T, Caceres D, Webb CM, Valdez LM, La Rosa M. Severe COVID-19 during pregnancy and possible vertical transmission. Am J Perinatol. 2020; 37 (8): $861-5$

13. Breslin N, Baptiste C, Gyamfi-Bannerman C, Miller R, Martinez R, Bernstein K, et al. COVID-19 infection among asymptomatic and symptomatic pregnant women: Two weeks of confirmed presentations to an affiliated pair of New York City hospitals. Am J Obstet Gynecol. 2020; 2 (2): 100118.

14. Breslin N, Baptiste C, Miller R, Fuchs K, Goffman D, Gyamfi-Bannerman C, et al. COVID-19 in pregnancy: early lessons. Am J Obstet Gynecol MFM. 2020; 2 (2): 100111.

15. Buonsenso D, Raffaelli F, Tamburrini E, Biasucci DG, Salvi $\mathrm{S}$, Smargiassi A, et al. Clinical role of lung ultrasound for the diagnosis and monitoring of COVID-19 pneumonia in pregnant women. Ultrasound Obstet Gynecol. 2020; 56 (1): 106-9.

16. Chen R, Zhang Y, Huang L, Cheng BH, Xia ZY, Meng QT. Safety and efficacy of different anesthetic regimens for parturients with COVID-19 undergoing Cesarean delivery: a case series of 17 patients. Can J Anaesth. 2020; 67 (6): 655-63.

17. Chen Y, Peng H, Wang L, Zhao Y, Zeng L, Gao H, et al. Infants born to mothers with a new coronavirus (COVID19). Front Pediat. 2020; 8: 104.

18. Fan C, Lei D, Fang C, Li C, Wang M, Liu Y, et al. Perinatal transmission of COVID-19 associated SARS-CoV-2: should we worry? Clin Infect Dis. 2020; 72 (5): 862-4.

19. Gidlöf S, Savchenko J, Brune T, Josefsson H. COVID-19 in pregnancy with comorbidities: more liberal testing strategy is needed. Acta Obstet Gynecol Scand. 2020; 99 (7): 948-9.

20. González Romero D, Ocampo Pérez J, González Bautista L, Santana-Cabrera L. Pronóstico perinatal y de la paciente embarazada con infección por COVID-19 [Pregnancy and perinatal outcomeof a womanwith COVID-19 infection]. Rev Clin Esp. 2020; 220 (8): 533-4.

21. Hantoushzadeh S, Shamshirsaz AA, Aleyasin A, Seferovic MD, Aski SK, Arian SE, et al. Maternal Death due to COVID-19 disease. Am J Obstet Gynecol. 2020; S00029378 (20): 30516-0.

22. Iqbal SN, Overcash R, Mokhtari N, Saeed H, Gold S, Auguste T, et al. An uncomplicated delivery in a patient with COVID-19 in the United States. N Engl J Med. 2020; 382 (16): e34.

23. Kalafat E, Yaprak E, Cinar G, Varli B, Ozisik S, Uzun C, et al. Lung ultrasound and computed tomographic findings in pregnant woman with COVID-19. Ultrasound Obstet Gynecol. 2020; 55 (6): 835-7.

24. Li N, Han L, Peng M, Lv Y, Ouyang Y, Liu K, et al. Maternal and neonatal outcomes of pregnant women with COVID-19 pneumonia: a case-control study. Clin Infect Dis. 2020; 71 (16): 2035-41.

25. Li Y, Zhao R, Zheng S, Chen X, Wang J, Sheng X, et al. Lack of vertical transmission of severe acute respiratory syndrome coronavirus 2, China. Emerg Infect Dis. 2020; 26 (6): $1335-6$

26. Liu D, Li L, Wu X, Zheng D, Wang J, Yang L, et al. Pregnancy and perinatal outcomes of women with coronavirus disease (COVID-19) pneumonia: a preliminary analysis. AJR Am J Roentgenol. 2020; 215 (1): 127-32.

27. Liu H, Liu F, Li J, Zhang T, Wang D, Lan W. Clinical and CT imaging features of the COVID-19 pneumonia: Focus on pregnant women and children. J Infect. 2020; 80 (5): e7-e13.

28. Liu Y, Chen H, Tang K, Guo Y. Clinical manifestations and outcome of SARS-CoV-2 infection during pregnancy. J Infect. 2020; S0163-4453(20)30109-2. 
29. Song L, Xiao W, Ling K, Yao S, Chen X. Anesthetic management for emergent cesarean delivery in a parturien with recent diagnosis of coronavirus disease 2019 (COVID19): a case report. Transl Perioper Pain Med. 2020; 7 (3): 234-7.

30. Wang S, Guo L, Chen L, Liu W, Cao Y, Zhang J, et al. A case report of neonatal COVID-19 infection in China. Clin Infect Dis. 2020; 71 (15): 853-7.

31. Wang X, Zhou Z, Zhang J, Zhu F, Tang Y, Shen X. A case of 2019 Novel Coronavirus in a pregnant woman with preterm delivery. Clin Infect Dis. 2020; 71 (15): 844-6.

32. Xia H, Zhao S, Wu Z, Luo H, Zhou C, Chen X. Emergency Caesarean delivery in a patient with confirmed coronavirus disease 2019 under spinal anaesthesia. Br J Anaesth. 2020; 124 (5): e216-e218.

33. Yan J, Guo J, Fan C, Juan J, Yu X, Li J, et al. Coronavirus disease 2019 (COVID-19) in pregnant women: A report based on 116 cases. Am J ObstetGynecol. 2020; 223 (1): 111.e1-e14.

34. Yu N, Li W, Kang Q, Xiong Z, Wang S, Lin X, et al. Clinical features and obstetric and neonatal outcomes of pregnant patients with COVID-19 in Wuhan, China: a retrospective, single-centre, descriptive study. Lancet Infect Dis. 2020; 20 (5): 559-64.

35. Zamaniyan M, Ebadi A, Aghajanpoor Mir S, Rahmani Z, Haghshenas M, Azizi S. Preterm delivery in pregnant woman with critical COVID-19 pneumonia and vertical transmission. Prenat Diagn. 2020; 40 (13): 1759-61.

36. Zambrano LI, Fuentes-Barahona IC, Bejarano-Torres DA, Bustillo C, Gonzales G, Vallecillo-Chinchilla G, et al. A pregnant woman with COVID-19 in Central America. Travel Med Infect Dis. 2020; 36: 101639.

37. Mendoza M, Garcia-Ruiz I, Maiz N, Rodo C, GarciaManau P, Serrano B, et al. Pre-eclampsia-like syndrome induced by severe COVID-19: a prospective observational study. BJOG. 2020; 127 (11): 1374-80.
38. Lam CM, Wong SF, Leung TN, Chow KM, Yu WC, Wong TY, et al. A case-controlled study comparing clinical course and outcomes of pregnant and non-pregnant women with severe acute respiratory syndrome. BJOG. 2004; 111 (8): $771-4$.

39. Zheng QL, Duan T, Jin LP. Single-cell RNA expression profiling of ACE2 and AXL in the human maternal- fetal interface. Reprod Dev Med. 2020; 4 (1): 7-10.

40. Wang CL, Liu YY, Wu CH, Wang CY, Wang CH, Long CY. Impact of COVID-19 on Pregnancy. Int J Med Sci. 2021; 18 (3): 763-7.

41. Blumberg D, Sridhar A, Lakshminrusimha S, Higgins RD, Saade G. COVID-19 Vaccine Considerations during Pregnancy and Lactation. Am J Perinatol. 2021; 38 (6): 523-8.

42. Male V. Are COVID-19 vaccines safe in pregnancy? Nat Rev Immunol. 2021; 21 (4): 200-1.

43. Zipursky JS, Greenberg RA, Maxwell C, Bogler T. Pregnancy, breastfeeding and the SARS-CoV-2 vaccine: an ethics-based framework for shared decision-making. CMAJ. 2021; 193 (9): E312-4

44. Carsetti R, Quintarelli C, Quinti I, Piano Mortari E, Zumla A, Ippolito G, et al. The immune system of children: the key to understanding SARS-CoV-2 susceptibility? Lancet Child Adolesc Health. 2020; 4 (6): 414-6.

45. Xia Wang, Wang X, Yang P, Zheng J, Liu P, Wei C, et al. Dynamic changes of acquired maternal SARS-CoV-2 IgG in infants. Sci Rep. 2021; 11 (1): 8021.

46. Rottenstreich A, Zarbiv G, Oiknine-Djian E, Zigron R, Wolf DG, Porat S. Efficient maternofetal transplacental transfer of anti- SARS-CoV-2 spike antibodies after antenatal SARS-CoV-2 BNT162b2 mRNA vaccination. Clin Infect Dis. 2021; ciab266. Epub ahead of print. 